\title{
Phytosterols in Wheat: Composition, Contents and Role in Human Health
}

\author{
Imene Rajhi', ${ }^{*}$, Bechir Baccouri² and Haythem Mhadhbi'
}

'Laboratory of Legumes, Center of Biotechnology of Borj Cedria, B.P. 901, Hammam-lif 2050, Tunisia; ${ }^{2}$ Laboratory of Olive Biotechnology, Center of Biotechnology of Borj Cedria B.P. 901, Hammam-lif 2050, Tunisia

*Corresponding author: Imene Rajhi, Laboratory of Legumes, Center of Biotechnology of Borj Cedria, B.P. 901, Hammam-lif 2050, Tunisia

\begin{abstract}
Phytosterols are plant components that have a chemical structure similar to cholesterol except for the addition of an extra methyl or ethyl group. In plants, more than 200 different types of phytosterols have been recorded such as $\beta$-sitosterol, campesterol, and stigmasterol. It is well reported that high consumption of plant sterols or stanols can lower serum total and low-density lipoprotein (LDL)-cholesterol concentrations in humans. In addition to their cholesterol lower effect, phytosterols have a promising effect in cancer prevention. The most important natural sources of phytosterol in human foods are oils and margarines. However cereal products are also recognized as an important natural source. It is known that wheat is a rich source of diverse sterols, either in their free, conjugated, or oxidized forms. Accumulated evidence showed that the health-promoting effects of wheat has been assigned to it unique phytochemical contents and profiles. Due to the rapid rate of discovery of wheat phytosterols, an updated summary is necessary to cover the current status. The major objective of this review is to summarize the important literature regarding phytosterols that were identified and characterized from wheat grains. Their genetic and environmental variations and their health effect were also investigated.
\end{abstract}

Keywords: Phytosterols; Wheat; Composition; Human health

\section{Introduction}

Sterols or steroid alcohols are a subgroup of the steroids. They present an important class of organic molecules. They found naturally in fungi (mycosterols), animals (zoosterols) and plants (phytosterols). Sterols can be also synthesized by some bacteria [1]. During recent years, there has been an increasing interest to sterols since they play an important role in human health. Plant sterols, also known as phytosterols, are found mainly in plant cell walls and membranes. Fruits, vegetables such as wheat germs, seeds, nuts, chocolate, margarines, avocados and vegetable oils are rich in sterols [2]. As shown in Figure 1 their structure is similar to cholesterol but they differ by the existence of an extra methyl or ethyl group or a double bound [3].

In plants, more than 200 different types of phytosterols have been recorded. Common phytosterols include sitosterol, campesterol, and stigmasterol [4]. Phytosterol compounds are particularly known for their ability to lower the serum total and low-density lipoprotein (LDL) cholesterol

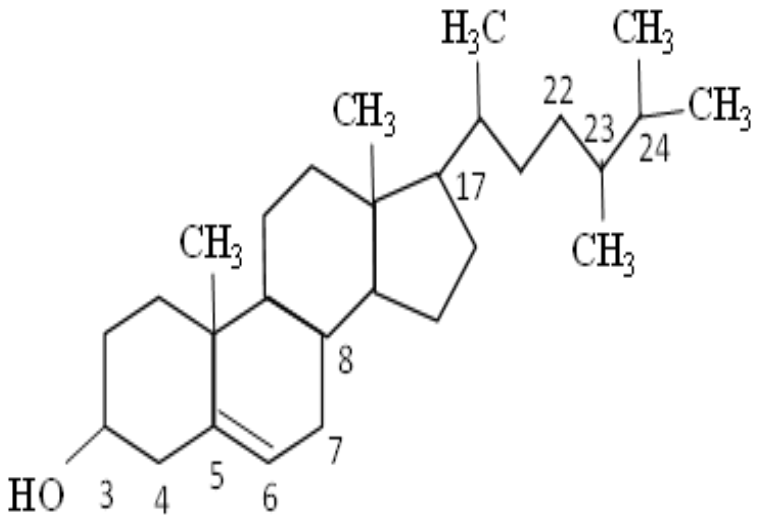

Figure 1: Chimical structure of B-sitosterol.

values by reducing the absorption of dietary and biliary cholesterol in the small intestine. Phytosterols compete with cholesterol for micelle formation in the intestinal lumen and inhibit cholesterol absorption. Also, phytosterols may prevent cancer and inhibit inflammation [5]. To produce functional foods, phytosterols are added to foods, such 
as spreads or yoghurt. However, the beneficial effects can also be achieved with moderately low doses obtained from natural sources as part of the normal daily diet. Therefore, cereal products may provide as a good natural alternative to enriched foods as source of phytosterol compounds. Cereals are an important natural source of plant bioactive and phytochimical substances, which they have a health promoting effects [6]. Wheat is one of the major cereal grains consumed worldwide. A wheat kernel is composed of three principal parts: the outer layer bran (14-16\%), the central endosperm (81-84\%) and the germ (2-3\%) [7]. The layers of bran comprise aleuronic layers, hyaline, testa and pericarp [8]. Whole grains compose micronutrients, dietary fibers and phytochemicals, which are considered to be responsible for their health benefit effects [9]. It is well known that wheat is a rich source of free, conjugated or oxidized forms of phytosterol [10].

Like many other phytochemicals, phytosterols are suggested to be concentrated in the bran and germ of the wheat grain, whereas steryl ferulates, a conjugated form of sterols, is accumulated only in the bran layers [11]. It has been reported that sterols, sterol glycosides, sterol esters, sterol ferulates, steroid hydrocarbons, and steroid ketones are present in the wheat bran [12]. The further distribution of sterol compounds in the various layers of the bran is not known. Furthermore, bran is regarded as a by- product in the common wheat milling process, and the refining of the wheat thus results in losses of the bioactive compounds. The utilization of phytosterol-rich bran fractions in foods would increase the intake of these compounds from natural sources. In the present review, the chemical structures of phytosterols, their variation in wheat, and their health effect will be examined.

\section{Chemical Structure of Phytosterols}

Phytosterols are steroid alcohols belonging to the triterpene family. They resemble cholesterol, the animal predominant sterol, both in their structure and function. These phytochemicals are synthesised from mevalonate via a complex enzymatic pathway. Mevalonate is first converted to squalene and then further to cycloartenol and other sterol compounds $[13,14]$. They are composed of a tetracyclic cyclopenta[a]phenantrene ring and a side chain attached to $\mathrm{C}-17$ (Figure 1). Sterols may have a double bond between $\mathrm{C}-5$ and $\mathrm{C}-6$ ( $\Delta-5$ phytosterols) or between C-7 and $\mathrm{C}-8(\Delta-7$ phytosterols). Based on the number of methyl groups in $\mathrm{C}-4$, sterols are classified as desmethyl (none), 4-monomethyl (one methyl group) or 4,4"-dimethyl sterols (two methyl groups). Furthermore, the structure of the side chain may differ; C-24 may be attached by a methyl, ethyl or ethylidene group, and there may be a double bond, e.g., between C-22 and C-23 [3]. Phytosterols exist in plants as free alcohols and as distinct conjugates. In steryl glycosides and acylated steryl glycosides, the hydroxyl group in C-3 is related with a glycosidic bond to a monosaccharide or to an esterified monosaccharide, respectively. Fatty acid ester conjugates have a fatty acid bound with the hydroxyl group. Additionally, phytosterolsmaybepresentas hydroxycinnamic acid esters esterified with ferulic or p-coumaric acid. The structural component of plant cell membranes is formed by free sterols, steryl glycosides and acylated steryl glycosides. These components are concentrated in certain parts of plasma and organelle membranes [15]. They may regulate the fluidity and permeability of the intracellular phospholipid bilayers and in some membranes. The glycosidic conjugates of sterols are synthesised in the cytosolic side of the plasma membrane, the glycosylation of membrane-bound free sterols resulting in alterations in the biophysical properties of the membrane [16]. The storage and transport forms of phytosterols are steryl fatty acid esters and they are possibly localised with triacylglycerols in the intracellular lipid droplets and spherosomes [17]. Phytosterols also have other potential functions in plant cells, e.g., serving as precursors or substrates for other steroid compounds, such as brassinosteroids and steroidal saponins [15].

\section{Phytosterols in Wheat}

The major dietary sources of phytosterols are vegetable oils, margarines, vegetable-fat spreads, bread and other cereal products, fruits and vegetables. Other sources of phytosterols include nuts, seeds and almonds. The cereals are only moderate in their sterol content when compared to vegetable oils, but they provide a significant amount of sterols to the diet due to the high amount typically consumed. The phytosterols are mainly located in the wheat kernel [9]. The total phytosterols in winter wheat grain range from $0.62-0.96 \mathrm{mg} / \mathrm{g}$ dry weight basis [7]. A majority of the sterols found in wheat are desmethyl sterols; 4-Monomethyl and 4'4- dimethyl sterols serve as precursors of desmethyl sterols and are found in low amounts. The main phytosterol species in wheat is sitosterol, followed by campesterol, the corresponding saturated stanol forms and stigmasterol (Figure 2). Other species include brassicasterol, $\Delta-5$ avenasterol, cycloartenol, $\Delta$-7-stigmastenol, $\Delta$-7-avenasterol and 24- methylenecycloartanol [18]. Several other minor sterol species have been identified in wheat, namely stigmastadienol, gramisterol, $\alpha$-amyrin and citrostadienol [11]. In wheat, phytosterols exist as free sterols, fatty acid or hydroxycinnamic acid esterified conjugates, glycosides or acylated glycosides [11]. Phytosterols are mainly located in the wheat kernel [19]. The phytosterol contents of the

Citation: Imene Rajhi1, ${ }^{*}$ Bechir Baccouri2 and Haythem Mhadhbi1, Phytosterols in Wheat: Composition, Contents and Role in Human Health.

Op Acc J Bio Sci \& Res 5(5)-2020.

DOI: 10.46718/JBGSR.2020.05.000132 

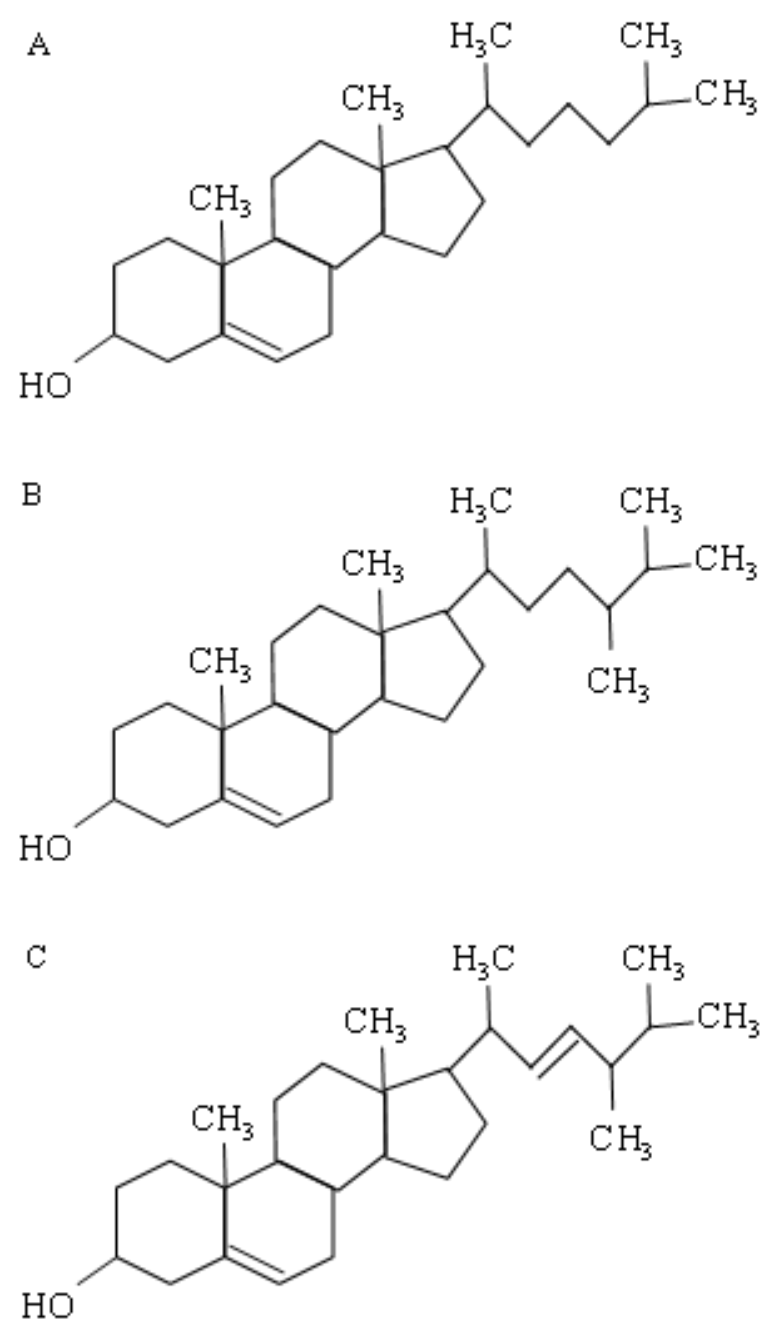

Figure 2: Structure of cholesterol (A), B-sitosterol and stigmasterol (C).

wheat dry fraction products in previous studies have varied considerably, from 300 to $4900 \mu \mathrm{g} / \mathrm{g}$ [18]. Wheat germ and bran are especially rich in phytosterols, containing 24004900 and $1200-2000 \mu \mathrm{g} / \mathrm{g}$ phytosterols, respectively. The aleurone fraction separated from bran also contains high levels of sterols. The poorest sources were refined wheat flours with low ash content, which contain approximately half of the amount of phytosterols compared to wholegrain wheat [18]. Total phytosterol content of flours increases with increasing ash content. The bran-rich fractions with varying ash and fiber contents obtained in various stages of the conventional milling process also had significant differences in phytosterol contents [20]. In wheat germ oil, very high sterol contents have been reported. The sterol composition varied in wheat fractions [21]. Sitosterol was the most abundant sterol species in all wheat types, comprising approximately $60 \%$ of the total content of phytosterols in whole wheat [6]. The sterol profile of wheat germ and flour fractions is characterized by a high content of sitosterol, whereas in bran fractions, the relative content of sitosterol is lower. The relative content of campesterol $(12-27 \%)$ is higher in the germ than in other wheat fractions. Germ is poor in stanols, since only $\mathbf{2 - 7 \%}$ of the total content is covered by sitostanol and campestanol. Stanols comprise up to $37 \%$ of total sterols in bran and up to $16 \%$ in flour fractions. The relative content of stigmasterol varies from 0-4\% depending on the wheat fraction [21].

\section{Phytosterols Variation in Wheat}

Natural variation creates a basis for enrichment of phytochemicals in foods. During the development of grain, wheat is exposed to a number of internal and external factors, which may alter its properties and characteristics. Genotype and environment conditions may have an impact on the composition of phytochemical compounds of cereal products.

\section{Genetic Variation}

Phytosterols composition varied depending on genotype. Chen and his colleagues [22] observed a significant cultivar effect in the contents of sitosterol, stigmasterol and campesterol within locations when the three bread wheat cultivars were grown at three locations in the state of Oklahoma (USA) in 2005. Significant genetic variation was also suggested in the contents of individual sterol compounds in bread wheat lines cultivated in France in 2006 [23]. In addition, the results of one study indicated significant differences in the phytosterol compositions of bread wheat, durum wheat, spelt and emmer wheat depending on genotype and species [23].

\section{Environmental Variation}

Wheat genotypes cultivated at different environments are exposed to different growing conditions (location, year, and soil properties), climatic conditions (amount of precipitation and temperature) and agronomic practices (irrigation and fertilization). The growing environment thus provides numerous variables, which may possibly affect the phytochemical content and other characteristics of wheat. Both growing location and genetic background affected the phytosterol content and composition of wheat cultivars [22]. The total phytosterol contents of wheat cultivars varied at most from 196 to $355 \mu \mathrm{g} / \mathrm{g} \mathrm{FW}$ among locations. It has been concluded that agronomic practices, climate and genotype significantly affected the wheat grain components [22]. The cultivation of the same cultivar in both dry and irrigated lands showed that irrigation seemed to result in lower of phytosterols, since its total phytosterol contents decreased from $315 \mu \mathrm{g} / \mathrm{g}$ (dryland) to $202 \mu \mathrm{g} / \mathrm{g}$ (irrigated). 
The significance of growing year in levels of phytosterols in wheat is not known. Alignan and his colleagues [23] compared two sowing dates during one growing season: conventional sowing in November 2005 and delayed sowing in January 2006 at one location in France. The sowing date did not affect the total phytosterol content of wheat cultivars. However, the contents of campesterol and sitostanol were affected, suggesting that the phytosterol composition may vary depending on the sowing date. The authors stated that this variation probably occurred due to differences in weather conditions (temperature and rainfall) during grain filling. The genotype effect was, however, found to be the main factor to cause variation in the phytosterol contents.

\section{Health Effect of Wheat Phytosterols}

Considered as cholesterol-like molecules, phytosterols are detected in all plants foods especially in vegetables oils including corn oil, sunflower oil, safflower oil, soybean oil, palm oil, and olive oil, with different contents $(952,725$, $444,221,49$, and $176 \mathrm{mg} / 100$ g edible portion, respectively [24]. Additionally, they are present in almonds, beans corn, wheat, lettuce, banana, apple, and tomato (with 143, 76, 70, $69,38,16,12$, and $7 \mathrm{mg} / 100$ g edible portion, respectively) [24]. The most consumed plant sterols are sitosterol (66\%), campesterol (22\%), stigmasterol (8\%), and sitostanol and campestanol (4\%) [25]. In spite of their absorption which occurs in small amounts, phytosterols inhibit the cholesterol absorption in the intestine by re-rotating the endogenous biliary cholesterol which is considered as the key stage in cholesterol elimination [26]. Phytosterols can prevent from different illness such as cancer, diabetes, obesity and cardiovascular diseases.

\section{Cholesterol Lowering Effect}

Over 60 years, phytosterols were defined as a lowering substance of serum cholesterols in human [27]. Phytosterols are presenting as esters (fatty acid and hydroxycinnamic) and glycosides [28]. In the gastro-intestinal tract, all esters links are divided by especial enzymes to finally deliver the free sterol forms [29]. These free sterols are then, consequently assimilated into mixed micelles by interfering with cholesterol incorporation. Such as cholesterol, phytosterols are absorbed from the mixed micelles by enterocytes via receptors (NPC1L1 which is placed in the intestinal apical membrane). These receptors diminish the absorption of both cholesterol and phytosterols [30].

\section{Anti-Cancer Effect}

It has been demonstrated that diets rich in phytosterols can reduce the risk of cancer with 20\% [31]. Phytosterols can prevent from breast, prostate, and colon cancers [32]. Many observational and epidemiologic studies confirm that people who consume a diet rich in phytosterols have lower frequency of tumors [33-35]. Thus, phytosterols act on host systems ability allowing antitumor responses such as their influence on the dependent hormonal growth of endocrine tumors, and improvement of immune detection of cancer [36]. Additionally, they inhibit the growth of tumors by diminishing

1. The progression of tumor cell cycle,

2. The initiation of apoptosis and

3. The metastasis of cancers $[37,38]$.

\section{Possible Anti-Obesity Effect}

Recently, obesity is known as a global health concern [39]. It can conduct to the evolution of chronic illnesses including diabetes, cancers and cardiovascular diseases [40]. Nowadays, in order to reduce the obesity, the investigation of anti-obesity products acquires much attention [41]. It is well known that a diete based on vegetables and fruits are related to a smaller obesity risk [42]. This advantageous effect may be related to the presence of phytosterols. Their anti-obesity effect was evaluated in animals. In fact, when the phytosterols were added to the diet the hepatic and plasma triglycerides concentrations were significantly decreased [43]. Clinical experiments suggest that the decrease in body weights could be assigned to the reduction in the absorption of fatty acids succeeding phytosterols consumption [43]. Also, it has been demonstrated that phytosterols can

1. Reduce levels of triglycerides and cholesterol in the fecal lipid excretion [44],

2. Improve insulin sensitivity [45],

3. Augment the adiponectin concentrations [46],

4. Activate the protein kinase [47], and

5. Inhibit the phospholipase [47].

\section{Anti-Cardiovascular Effect}

The cardiovascular diseases are the major cause of death for the type 2 diabetic patients. Type 2 diabetic individuals presented dyslipidemia distinguished by lipoprotein and lipid aberrations [48]. One of the proposed strategies to control blood lipids is the consumption of plant sterols which can decrease both LDL and triglycerides concentrations [49]. Thus, phytosterols can prevent the cardiovascular diseases.

\section{Conclusion}

Plant sterols or phytosterols are present in fruits and

Citation: Imene Rajhi1, ${ }^{*}$ Bechir Baccouri2 and Haythem Mhadhbi1, Phytosterols in Wheat: Composition, Contents and Role in Human Health. 
vegetables. They are absorbed in tiny and significant amounts from our diet. Many studies have been demonstrated that the consumption of phytosterols is associated to many health benefits including prevention to

1. Different types of cancers,

2. Obesity,

3. Cardiovascular diseases, and the most important effect is the lowering of cholesterol and triglycerides in blood.

\section{References}

1. We JH, Yin X, Welander PV (2016) Sterol Synthesis in Diverse Bacteria. Frontiers in Microbiology 7: 990.

2. Othman RA, Myrie SB, Jones PJ (2013) Non-cholesterol sterols and cholesterol metabolism in sitosterolemia. Atherosclerosis 231: 291-299.

3. Moreau RA, Whitaker BD, Hicks KB (2002) Phytosterols, phytostanols, and their conjugates in foods: structural diversity, quantitative analysis, and health-promoting uses. Prog Lipid Res 41(6): 457-500.

4. Lagarda MJ, Garcia-Llatas G, Farre R (2006) Analysis of phytosterols in foods. J. Pharm. Biomed. Anal. 41: 1486-1496.

5. Othman RA, Moghadasian MH (2011) Beyond cholesterollowering effects of plant sterols: clinical and experimental evidence of anti-inflammatory properties. Nutr Rev 69(7): 371-382.

6. Gani A, Wani SM, Masoodi FA, Gousia Hameed (2012) WholeGrain Cereal Bioactive Compounds and Their Health Benefits. J Food Process Technol 3: 3.

7. Stevenson L, Phillips F, O'Sullivan K, Walton J (2012) Wheat bran: its composition and benefits to health, a European perspective. Int. J. Food Sci. Nutr 63: 1001-1013.

8. Surget A, Barron C (2005) Histologie du grain de blé. Industries des céréales 145(145): 3-7.

9. Fardet A (2010) New hypotheses for the health-protective mechanisms of whole-grain cereals: what is beyond fibre? Nutr Res Rev 23(1): 65-134.

10. Iwatsuki K, Akihisa T, Tokuda H, Ukiya M (2003) Sterol ferulates, sterols, and 5-alk(en)ylresorcinols from wheat, rye, and corn bran oils and their inhibitory effects on Epstein-Barr virus activation. J. Agric. Food Chem 51: 6683-6688.

11. Nyström L, Paasonen A, Lampi AM, Piironen V (2007) Total plant sterols, steryl ferulates and steryl glycosides in milling fractions of wheat and rye. J Cereal Sci 45(1): 106-115.

12. Prinsen P, Gutierrez A, Faulds CB, del Rio JC (2014) Comprehensive study of valuable lipophilic phytochemicals in wheat bran. J. Agric. Food Chem. 62: 1664-1673.

13. Goodwin TW (1980) Biosynthesis of sterols, in The Biochemistry of Plants, Vol 4, Lipids: Structure and Function. Ed by Stumpf PK and Conn EE. Academic Press, London pp 485-507.

14. Schaller $H$ (2003) The role of sterols in plant growth and development. Prog Lipid Res 42(3):163-175.

15. Piironen V, Lindsay DG, Miettinen TA, Toivo J, Lampi AM (2000)
Plant sterols: biosynthesis, biological function and their importance to human nutrition. J Sci Food Agric 80(7):939966.

16. Cacas J-L, Furt F, Le Guédard M, Schmitter J-M, Buré C, et al. (2012) Lipids of plant membrane rafts. Progress in Lipid Res 51(3): 272-299.

17. Gondet L, Bronner R, Benveniste P (1994) Regulation of sterol content in membranes by subcellular compartmentation of steryl-esters accumulating in a sterol-overproducing tobacco mutant. Plant Physiol 105(2): 509-518.

18. Piironen V, Toivo J, Lampi AM (2002) Plant sterols in cereals and cereal products. Cereal Chem. 79(1): 148-154.

19. Poudel R, Bhatta M (2017) Review on neutral-ceutical properties of whole wheat. Journal of nutrition Food science and technology. 7: 571.

20. Sramkova Z, Gregova E, Sturdik E (2009) chemical composition and nutritional quality of wheat gran. Acta Chimica Slovaka 2: 115-132

21. Yang $T$ (2005) Phytosterol in cereal by-product. Journal of the American Oil Chemists' Society JAOCS 82: 439-444.

22. Chen Y, Dunford NT, Edwards J, Carver B, Goad C (2009) Genotype and environment affect phytosterol content and composition of wheat. Cereal Chem 86(1): 96-99.

23. Alignan M, Roche J, Bouniols A, Cerny M, Mouloungui Z, Merah O (2009) Effects of genotype and sowing date on phytostanol-phytosterol content and agronomic traits in wheat under organic agriculture. Food Chem 117(2): 219225.

24. Weirauch JL, Gardner JM (1978) Sterol content of foods of plant origin. J. Am. Diet. Assoc 73: 39-47.

25. Vahouny GV, Mayer RM, and Treadwell CR. (1960) Comparison oflymphatic absorption of dihydrocholesterol and cholesterol in rat. Arch Biochem Biophys 86: 215-218.

26. Richard E. Ostlund J (2002) Phytosterols in human nutrition. Annu. Rev. Nutr.. 22: 533-549.

27. Peterson DW (1951) Effect of soybean sterols in the diet on plasma and liver cholesterolin chicks. Proc. Soc. Exp. Biol. Med. 78: 143-147.

28. Siperstein MD, Chaikoff IL, and Reinhardt WO (1952) C14cholesterol. V. Obligatory function of bile in intestinal absorption of cholesterol. J Biol Chem 198: 111-114.

29. Nissinen M, Gylling H, Vuoristo M, Miettinen TA (2002) Micellar distribution of cholesterol and phytosterols after duodenal plant stanol ester infusion. Am J Physiol Gastrointest Liver Physiol 282: G1009-1015.

30. Vanhanen HT, Blomqvist S, Ehnholm C, Hyvo“nen M, Jauhiainen M, et al. (1993) Serum cholesterol, cholesterol precursors, and plant sterols in hypercholesterolemic subjects with different apoE phenotypes during dietary sitostanol ester treatment. J Lipid Res 34: 1535-1544.

31. Welden G Prince J (2007) Plant Compounds Continue to Challenge Science, The American Institute for Cancer Research, Mol. Nutr. Food Res 51: 161-170.

32. Bradford PG, Awad AB (2007) Phytosterols as anticancer compounds. Mol Nutr Food Res 51(2): 161-170.

33. Sanders D J, Minter H J, Howes D, Hepburn PA (2000) Safety evaluation of phytosterol esters. Part 6 . The comparative absorption and tissue distribution of phytosterols in the rat.

Citation: Imene Rajhi1, ${ }^{*}$ Bechir Baccouri2 and Haythem Mhadhbi1, Phytosterols in Wheat: Composition, Contents and Role in Human Health. 
Food Chem. Toxicol. 38: 485-491.

34. Shimizu H, Ross RK, Bernstein L, Yatani R (1991) Cancers of the prostate and breast among Japanese and white immigrants in Los Angeles County. Br. J. Cancer 63: 963-966.

35. Barba M, Fuhrman B, Teter B, Muti P (2006) Epidemiology of breast, prostate, and colon cancers, in: Awad, A. B., Bradford, P. G. (Eds.), Nutrition and Cancer Prevention. CRC Taylor and Francis, Boca Raton p. 3-25.

36. Gutendorf B, Westendorf J (2001) Comparison of an array of in vitro assays for the assessment of the estrogenic potential of natural and synthetic estrogens, phytoestrogens and xenoestrogens. Toxicology, $166: 79-89$.

37. Awad A B,Williams H, Fink C S (2001) Phytosterols reduce in vitro metastatic ability of MDA-MB-231 human breast cancer cells. Nutr. Cancer 40: 157-164.

38. Choi YH, Kong KR, Kim YA, Jung KO (2003) Induction of Bax and activation of caspases during b-sitosterol- mediated apoptosis in human colon cancer cells. Int. J. Oncol 23: 16571662.

39. Smith KB, Smith MS (2016) Obesity statistics. Primary Care: Clinics in office practice 43: 121-135.

40. Barouki R, Gluckman PD, Grandjean P, Hanson M, Heindel JJ (2012) Developmental origins of non-communicable disease: Implications for research and public health. Environmental Health 11-42.

41. Colalto C (2018) What phytotherapy needs: Evidence-based guidelines for better clinical practice. Phytotherapy Research 32: 413-425.

42. Yu ZM, Declercq V, Cui Y, Forbes C, Grandy S, et al. (2018) Fruit and vegetable intake and body adiposity among populations in Eastern Canada: The Atlantic Partnership for Tomorrow's Health Study. BMJ Open 8.
43. Rideout TC, Harding SV, Jones PJ (2010) Consumption of plant sterols reduces plasma and hepatic triglycerides and modulates the expression of lipid regulatory genes and de novo lipogenesis in C57BL/6J mice. Molecular Nutrition \& Food Research, 54: 7-13.

44. Suzuki K, Konno R, Shimizu T, Nagashima T, Kimura A (2007) A fermentation product of phytosterol including campestenone reduces body fat storage and body weight gain in mice. Journal of Nutritional Science and Vitaminology 53: 63-67.

45. Xiong $M$, Huang $Y$, Liu Y, Huang M, Song G, et al (2018) Antidiabetic Activity of Ergosterol from Pleurotus Ostreatus in KK-A(y) Mice with Spontaneous Type 2 Diabetes Mellitus. Molecular Nutrition \& Food Research 62.

46. Collins M, Varady KA, Jones PJ (2007) Modulation of apolipoprotein $\mathrm{A} 1$ and $\mathrm{B}$, adiponectin, ghrelin, and growth hormone concentrations by plant sterols and exercise in previously sedentary humans. Canadian Journal of Physiology and Pharmacology 85: 903-910.

47. Ahmada C, SaenzT, Garcia D, de la Puerta R, Fernandez A, Martinez E (1997) The effects of a triterpene fraction isolated from Crataegus monogyna Jacq. on different acute inflammation models in rats and mice. Leucocyte migration and phospholipase A2 inhibition.The Journal of Pharmacy and Pharmacology 49: 329-331.

48. Trautwein EA, Koppenol PW, de Jong A, Hiemstra $H$, Vermeer MA, et al. (2018) Plant sterols lower LDL-cholesterol and triglycerides in dyslipidemic individuals with or at risk of developing type 2 diabetes; a randomized, double-blind, placebo-controlled study. Nutrition and Diabetes 8: 30.

49. Baker WL, Baker EL, Coleman Cl (2009) The effect of plant sterols or stanols on lipid parameters in patients with type 2 diabetes: a meta-analysis. Diabetes Res. Clin. Pract. 84: 3337.

\footnotetext{
*Corresponding author: Imene Rajhi, Email: imenrajhi@yahoo.fr

Next Submission with BGSR follows:

- Rapid Peer Review

- Reprints for Original Copy

- E-Prints Availability

- Below URL for auxiliary Submission Link: https://biogenericpublishers.com/submit-manuscript/
} 